\title{
Análise histopatológica de ratos cronicamente expostos por inalação ao herbicida ácido 2,4-Diclorofenoxiacético (2,4-D)
}

Histopathological analysis of rats chronically exposed by inhalation to the herbicide 2,4Dichlorophenoxyacetic acid (2,4-D)

Análisis histopatológico de ratos expuestas crónicamente por inhalación al herbicida ácido 2,4diclorofenoxiacético (2,4-D)

\author{
Gabriela Vidotto Cavallieri \\ ORCID: https://orcid.org/0000-0002-8058-1292 \\ Universidade do Oeste Paulista, Brasil \\ E-mail: gabi_vidotto@hotmail.com \\ Geovana Letícia Fernandes de Oliveira \\ ORCID: https://orcid.org/0000-0002-0308-2086 \\ Universidade do Oeste Paulista, Brasil \\ E-mail: leticiafernandes2709@hotmail.com \\ Gisele Alborghetti Nai \\ ORCID: https://orcid.org/0000-0003-1674-7371 \\ Universidade do Oeste Paulista, Brasil \\ E-mail: patologia@unoeste.br \\ Edson Assunção Mareco \\ ORCID: https://orcid.org/0000-0002-3504-6936 \\ Universidade do Oeste Paulista, Brasil \\ E-mail: edson@unoeste.br \\ Matheus Ribeiro Bizuti \\ ORCID: https://orcid.org/0000-0001-6679-0875 \\ Universidade Federal da Fronteira Sul, Brasil \\ E-mail: matheus_ribeiro.bizuti@hotmail.com \\ Debora Tavares de Resende e Silva \\ ORCID: https://orcid.org/0000-0002-3813-7139 \\ Universidade Federal da Fronteira Sul, Brasil \\ E-mail: debora.silva@uffs.edu.br \\ Ana Karina Marques Salge \\ ORCID: https://orcid.org/0000-0003-2718-1625 \\ Universidade Federal de Goiás, Brasil \\ E-mail: anasalge@ hotmail.com \\ Renata Calciolari Rossi \\ ORCID: https://orcid.org/0000-0002-3311-064X \\ Universidade do Oeste Paulista, Brasil \\ E-mail: renatacalciolari@terra.com.br
}

\begin{abstract}
Resumo
A expansão do consumo do 2,4-D traz preocupações em relação ao meio ambiente e principalmente a saúde humana, pois a exposição a esse agente químico poderá gerar efeitos nocivos ao organismo. O objetivo da presente pesquisa foi avaliar histopatologicamente o epitélio nasal e o perfil hematológico de ratos submetidos à pulverização crônica por via inalatória do herbicida 2,4-D. Foram utilizados 40 ratos Wistar adultos machos, divididos em 4 grupos, sendo eles: Grupo Controle (GC), Grupo Baixa Concentração (GBC), Grupo Média Concentração (GMC) e Grupo Alta concentração (GAC). O Protocolo de exposição foi realizado através de 2 caixas ligadas a 2 dois nebulizadores ultrassônicos, que realizaram a pulverização diária do herbicida por 15 minutos, durante 6 meses. Após o período de exposição, foi feita a coleta de amostra de sangue para confecção do hemograma e coleta e análise do epitélio nasal para quantificação dos mastócitos e infiltrado inflamatório. Houve diferença estatisticamente significativa em relação aos valores de Concentração de Hemoglobina Corpuscular Média (CHCM) do GBC quando comparado ao GC, porém o GC estava com valores elevados e o GBC estava com valores dentro dos padrões de normalidade. Em relação aos outros parâmetros hematológicos avaliados, os mastócitos e o infiltrado inflamatório não foram observados diferença estatisticamente significativa dos grupos expostos ao herbicida 2,4-D quando comparados ao GC. Sendo assim, o herbicida 2,4-D não demonstrou toxicidade aos parâmetros hematológicos e epitélio nasal de ratos Wistar após exposição crônica inalatória no período de 6 meses quando comparados ao grupo controle.
\end{abstract}


Palavras-chave: Contagem de células sanguíneas; Mucosa nasal; Ratos; Mucosa Respiratória; Sistema respiratório; Toxicidade.

\begin{abstract}
The expansion of 2,4-D consumption raises concerns about the environment and especially human health, as exposure to this chemical agent can cause harmful effects to the body. The aim of this research was to histopathologically evaluate the nasal epithelium and the hematological profile of rats submitted to chronic inhaled spraying of the 2,4-D herbicide. Forty adult male Wistar rats were used, divided into 4 groups, namely: Control Group (GC), Low Concentration Group (GBC), Medium Concentration Group (GMC) and High Concentration Group (GAC). The exposure protocol was carried out using 2 boxes connected to 2 ultrasonic nebulizers, which sprayed the herbicide daily for 15 minutes for 6 months. After the exposure period, a blood sample was collected to prepare the blood count and collection and analysis of the nasal epithelium to quantify the mast cells and inflammatory infiltrate. There was a statistically significant difference in relation to the Mean Corpuscular Hemoglobin Concentration (CHCM) values of the GBC when compared to the CG, but the CG had high values and the GBC had values whin the normal range. Regarding the other hematological parameters evaluated, mast cells and inflammatory infiltrate were not observed statistically significant differences in the groups exposed to the 2,4-D herbicide when compared to the CG. Thus, the 2,4-D herbicide showed no toxicity to hematological parameters and nasal epithelium of Wistar rats after chronic inhalation exposure for a period of 6 months when compared to the control group.
\end{abstract}

Keywords: Blood cell count; Nasal mucosa; Rats; Respiratory mucosa; Respiratory system; Toxicity.

\begin{abstract}
Resumen
La expansión del consumo de 2,4-D genera preocupaciones sobre el medio ambiente y especialmente la salud humana, ya que la exposición a este agente químico puede causar efectos nocivos para el cuerpo. El objetivo de esta investigación fue evaluar histopatológicamente el epitelio nasal y el perfil hematológico de ratones sometidos a aspersión crónica inhalada del herbicida 2,4-D. Se utilizaron cuarenta ratones Wistar macho adultos, divididos en 4 grupos, a saber: Grupo de control (GC), Grupo de baja concentración (GBC), Grupo de concentración media (GMC) y Grupo de alta concentración (GAC). El protocolo de exposición se llevó a cabo utilizando 2 cajas conectadas a 2 nebulizadores ultrasónicos, que rociaron el herbicida diariamente durante 15 minutos durante 6 meses. Después del período de exposición, se tomó una muestra de sangre para preparar el recuento sanguíneo y la recolección y análisis del epitelio nasal para cuantificar los mastocitos y el infiltrado inflamatorio. Hubo una diferencia estadísticamente significativa en relación a los valores de Concentración de Hemoglobina Corpuscular Media (CHCM) del GBC en comparación con el GC, pero el GC tuvo valores altos y el GBC tuvo valores dentro del rango normal. En cuanto al resto de parámetros hematológicos evaluados, los mastocitos y el infiltrado inflamatorio no se observaron diferencias estadísticamente significativas en los grupos expuestos al herbicida 2,4-D en comparación con el GC. Por lo tanto, el herbicida 2,4-D no mostró toxicidad para los parámetros hematológicos y el epitelio nasal de las ratones Wistar después de la exposición crónica por inhalación durante un período de 6 meses en comparación con el grupo de control.
\end{abstract}

Palabras clave: Recuento de células sanguíneas; Mucosa nasal; Ratones; Mucosa respiratoria; Sistema respiratorio; Toxicidad.

\title{
1. Introdução
}

O Brasil está entre os países que são considerados os maiores produtores agropecuários, além de ser o segundo que mais exporta agroquímico, no qual apresenta fundamental importância na economia local (Pignati et al. 2017). Além disso, o país se tornou campeão em vendas de defensivos agrícolas no ranking mundial desde o ano de 2008, quando movimentou cerca de R\$ 7 bilhões no mercado de agrotóxicos, o qual ultrapassou mais que o dobro do crescimento do mercado global expandindo seu mercado em 190\% (Londres, 2011).

Em relação a aplicação dos agrotóxicos sobre o alvo, são utilizadas técnicas de aplicações variadas, dentre elas, apesar dos impactos ao meio ambiente e à saúde, é a pulverização aérea (Ferreira, 2015). Há evidência de que a pulverização aérea apresenta uma alta periculosidade devido a ocorrência da "deriva técnica", que é quando o defensivo agrícola atinge outras áreas, além do alvo desejado, aproximadamente, $32 \%$ do agrotóxico aplicado fica retido nas plantas, $49 \%$ atingem os solos e 19\% atingem áreas circunvizinhas disseminados pelo ar (Chaim, 2004).

O manejo dos agrotóxicos também é um fato importante a ser considerado, visto que o manejo inadequado trará maiores riscos ao ambiente e a saúde dos trabalhadores e pesquisadores já observaram que grande parte dos agricultores realizam o transporte, armazenamento e, principalmente, descarte das embalagens de forma inadequada demonstrando a 
necessidade de se intensificar as orientações quanto ao manejo desses produtos de forma a não trazer grandes riscos à saúde e ao ambiente (Pedroso et al., 2020).

Dentre os diversos defensivos agrícolas comercializados e disseminados no Brasil, está o herbicida ácido 2,4diclorofenoxiacético (2,4-D), o qual vem sendo utilizado no controle de várias plantas que interferem negativamente na agricultura, em plantações de cereais, cana-de-açúcar, controle florestal e pomares. O 2,4-D pertence à classe dos ácidos fenoxiacéticos, foi o primeiro a ser introduzido no Brasil, é um dos mais utilizado no Brasil e no mundo, e continua sendo um dos defensivos agrícolas mais estudados, tanto em animais quanto em humanos, principalmente pelo fato de que os mecanismos exatos relacionados aos efeitos tóxicos do 2,4-D não estão esclarecidos (Dakhakhni, Raouf \& Qusti, 2016).

A Agência de Proteção Ambiental dos Estados Unidos da América (EPA) (2005) classifica o 2,4-D como categoria de toxicidade III ou IV por exposição via oral, dérmica e inalatória. Além disso, revelam que o herbicida não é um irritante da pele (Categoria de Toxicidade III ou IV) e embora as formas de éster de 2,4-D não sejam irritantes para os olhos (Categoria de toxicidade III ou IV), as formas ácidas e salinas são consideradas irritantes oculares graves (Categoria de toxicidade I).

Os estudos sobre os efeitos do 2,-D em todo o organismo são amplos. Em relação a exposição inalatória ao 2,4-D, já foi observado que em média e alta doses do herbicida, na exposição aguda, induziu danos ao DNA no ensaio do cometa, independente dos tempos diferentes de exposições. Além disso, o mesmo estudo também demonstrou que tanto a exposição inalatória aguda, quanto a exposição inalatória e oral crônica causaram efeitos genotóxicos nos ratos expostos (Mello et al.2020). Também há indícios de alterações neurológicas provocadas pela exposição ao 2,4-D. Ueda et al (2021), por meio da exposição oral e inalatória de ratos adultos a diferentes concentrações ao 2,4-D, observaram que a exposição crônica, por um período de 6 meses, a altas concentrações do herbicida alterou a capacidade dos animais em reconhecer os objetos, sendo a alteração pior para os animais expostos por via oral, comparado aos expostos por inalação do agrotóxico.

Por fim, estudos anteriores já demonstraram que a exposição oral ao 2,4 pode causar alterações no perfil hematológico e no sistema respiratório, tanto em animais quanto em humanos, por meio da presença de rinite e alterações dos níveis de hemoglobina no sangue (Slager et al. 2009. Slager et al. 2010. Wafa et al. 2017).

Portanto, pesquisas sobre quais são os efeitos da exposição crônica ao 2,4-D nas células sanguíneas e no sistema respiratório são de grande relevância devido a utilidade dos dados na compreensão dos efeitos do herbicida no organismo humano, principalmente para trazer evidências de como a exposição inalatória ao herbicida pode afetar o sistema respiratório superior, já que a maioria dos estudos investigam o trato respiratório inferior. Além disso, relevância do estudo se dá pelo fato de simulador a real exposição dos trabalhadores e populações expostas a pulverização aérea do herbicida.

Sendo assim, o objetivo desta pesquisa foi avaliar histopatologicamente os parâmetros hematológicos e o epitélio nasal de ratos submetidos à exposição crônica inalatória ao herbicida 2,4-D.

\section{Metodologia}

\section{Aspectos da natureza ética}

Trata-se de um estudo experimental, transversal e com abordagem quantitativa (Koche, 2011) que foi submetido e aprovado pela Comissão de Ética no Uso de Animais (CEUA) da Unoeste sob o n ${ }^{\circ} 4099$ e foi realizado de acordo com o Guia para o Cuidado e Uso de Animais de Laboratório do Instituto Nacional de Saúde (USA).

\section{Animais e ambiente de experimentação}

Para a realização do experimento, foram utilizados 40 ratos Wistar adultos machos $(400 \mathrm{~g})$, alocados em gaiolas

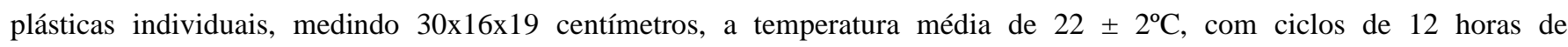
luminosidade, sendo das 07:00 às 19:00 horas (período claro) e 19:00 às 07:00 horas (período escuro). Os animais receberam dieta padrão para animais de laboratório (Supralab®, Alisul, Brasil) e água ad libitum. 
Os animais foram divididos aleatoriamente em quatro grupos, sendo 10 animais em cada grupo, de acordo com a Tabela 1 .

Tabela 1. Divisão dos grupos e os valores das concentrações do 2,4-D.

\begin{tabular}{lcc}
\hline \multicolumn{1}{c}{ Grupo Experimental } & Sigla & Concentração de Exposição ao 2,4-D* \\
\hline Controle & GC & 0 (10 ml de água destilada $)$ \\
Baixa Concentração & GBC & $3,71 \times 10^{-3}$ \\
Média Concentração & GMC & $6,17 \times 10^{-3}$ \\
Alta Concentração & GAC & $9,28 \times 10^{-3}$ \\
\hline
\end{tabular}

Legenda: *Em grama de ingrediente ativo/hectare (g.i.a/ha), considerando experimento ambientalmente relevante segundo forma de aplicação do produto. Fonte: Autores.

Todas as concentrações do 2,4-D foram diluídas em $10 \mathrm{ml}$ de água destilada. O tempo de exposição ao herbicida foi de 15 minutos diários para cada grupo, nebulizados em 5 dias consecutivos da semana (segunda à sexta) a fim de simular a exposição ocupacional.

As concentrações utilizadas foram baseadas na recomendação do fabricante para uso agrícola, especificado na bula, do 2,4-D ® (Formulação comercial, 67,0\% m/v, Nortox, Paraná, Brasil) de acordo com as medidas das caixas em que os animais permaneciam durante a exposição, mimetizando o volume do ambiente, sendo feitos ajustes para a caixa baseado na exposição ambiental (Mello et al., 2018).

$\mathrm{O}$ protocolo de experimentação contou com duas caixas $(32 \mathrm{x} 24 \mathrm{x} 32 \mathrm{~cm})$ cada uma ligada a um nebulizador ultrassônico da marca Pulmosonic Star®. Uma caixa foi destinada aos animais do GC e a outra caixa aos animais do GBC, GMC e GAC. Os 10 animais de cada grupo eram nebulizados juntos, na ordem da menor concentração para a maior.

Todos os animais foram expostos durante 6 meses e após este período foram eutanasiados. A anestesia e eutanásia foram realizadas com Tiopental sódico (Syntec, EUA), nas doses de $100 \mathrm{mg} / \mathrm{Kg}$ de peso, administrado na cavidade peritoneal. Os indicativos de morte foram a ausência de movimentos respiratórios, batimentos cardíacos e perda dos reflexos.

Foi coletado $2 \mathrm{ml}$ de sangue de cada animal, por meio de punção intracardíaca, para a confecção do hemograma. O analisador hematológico modelo POCH-100iV DIFF (Sysmex do Brasil Indústria e Comércio LTDA®, Curitiba/PR-Brasil) foi utilizado para analisar as plaquetas, as séries vermelha e branca.

Após a eutanásia dos animais, o focinho de cada rato foi retirado para a realização da análise histológica. Os focinhos foram fixados em formaldeído a $10 \%$ e em seguida emblocados em parafina. Os blocos foram cortados em micrótomo eletrônico na espessura de $5 \mu \mathrm{m}$ e corados por Hematoxilina-Eosina (HE) para a quantificação dos leucócitos totais, onde as células coram-se de roxo e o citoplasma em rosa. Para a quantificação dos mastócitos, foi utilizada a coloração de Azul de toluidina, corando as células na cor azul.

Após a confecção das lâminas, foram capturadas imagens em microscópio com câmera acoplada (Leica ICC50 HD) para analisa-las morfometricamente. Foi utilizado o software Image-Pro Plus® (Versão 7.0, Media Cybernetics, Silver Spring, MD, USA) para quantificar os mastócitos e o infiltrado inflamatório que estavam na lâmina própria, em toda extensão do corte.

As lâminas contendo os cortes histológicos foram cegadas para que os examinadores não soubessem o grupo analisado e, desta forma, emitissem falsos resultados.

\section{Análise Estatística}

Os dados foram submetidos à análise de distribuição normal por meio do teste de Shapiro-Wilk disponível no programa R (versão 3.2.3). Como os dados não apresentaram uma distribuição normal, foi utilizado o teste de Kruskal-Wallis 
seguido do teste de Dunn, para análise da diferença entre os grupos. Foram considerados significativos os valores que apresentaram $\mathrm{p}<0,05$.

\section{Resultados}

Não houve morte de nenhum animal durante o período experimental de exposição crônica inalatória ao herbicida 2,4D até a data da eutanásia, demonstrando que as concentrações utilizadas durante o tempo de exposição ao herbicida não tiverem efeito letal.

Entre todos os aspectos avaliados, tanto para os parâmetros hematológicos, quanto para a quantificação dos mastócitos e infiltrado inflamatório, a única diferença estatisticamente significativa encontrada em comparação ao GC foi em relação aos valores de Concentração de Hemoglobina Corpuscular Média (CHCM) do GBC, entretanto o GC estava com valores de CHCM acima dos valores de referência e o GBC estava com valores dentro dos padrões de normalidade (Tabela 2), o que não deixou claro se houve influência da exposição ao herbicida no resultado desse parâmetro.

A microcitose, caracterizada pela redução dos valores de $\mathrm{VCM}$, foi encontrada em todos os animais do presente estudo, sendo mais acentuada no GAC quando comparada ao GMC, porém não houve diferença dos grupos ao compará-los com o GC, demonstrando que a exposição crônica inalatória ao 2,4-D não foi a responsável pela microcitose existente.

Tabela 2. Parâmetros hematológicos, quantificação dos mastócitos e infiltrado inflamatório comparados entre os grupos de estudo.

\begin{tabular}{|c|c|c|c|c|c|c|}
\hline $\begin{array}{l}\text { Parâmetros } \\
\text { Hematológicos }\end{array}$ & $\begin{array}{l}\text { Valores de } \\
\text { referências }\end{array}$ & GC & GBC & GMC & GAC & Valor de $p$ \\
\hline $\begin{array}{l}\text { Eritrócitos } \\
\left(\mathbf{X 1 0} \% \mathbf{m m}^{3}\right)\end{array}$ & $6,5-7,9$ & $\begin{array}{c}9,5 \\
(9,2-9,7)\end{array}$ & $\begin{array}{c}10,1 \\
(9,8-10,3)\end{array}$ & $\begin{array}{c}9,6 \\
(9,4-9,9)\end{array}$ & $\begin{array}{c}10 \\
(10-10,1)\end{array}$ & 0,1431 \\
\hline Hemoglobina (g/dl) & $14,2-15,9$ & $\begin{array}{c}17,5 \\
(17-17,8)\end{array}$ & $\begin{array}{c}17,8 \\
(17,6-18)\end{array}$ & $\begin{array}{c}18,1 \\
(16,8-18,1)\end{array}$ & $\begin{array}{c}18,2 \\
(17,8-18,5)\end{array}$ & 0,297 \\
\hline Hematócrito (\%) & $44-49$ & $\begin{array}{c}50,9 \\
(50,6-52,1)\end{array}$ & $\begin{array}{c}54,4 \\
(52,8-55,1)\end{array}$ & $\begin{array}{c}53,7 \\
(50,1-55,2)\end{array}$ & $\begin{array}{c}52,8 \\
(52-53,6)\end{array}$ & 0,2244 \\
\hline HCM (pg) & $19,8-21,9$ & $\begin{array}{c}18,4 \\
(18,3-18,7)\end{array}$ & $\begin{array}{c}17,6 \\
(17,6-17,8)\end{array}$ & $\begin{array}{c}18,2 \\
(18-18,4)\end{array}$ & $\begin{array}{c}18,3 \\
(18,2-18,4)\end{array}$ & 0,0622 \\
\hline СHCM (\%) & $31,5-33,6$ & $\begin{array}{c}34,2^{\mathrm{ab}} \\
(33,6-34,4)\end{array}$ & $\begin{array}{c}32,7^{\mathrm{c}} \\
(32,7-33,2)\end{array}$ & $\begin{array}{c}33,0^{\mathrm{bc}} \\
(33,0-33,3)\end{array}$ & $\begin{array}{c}34,3^{\mathrm{a}} \\
(34,2-34,3)\end{array}$ & $0,0003 *$ \\
\hline $\operatorname{VCM}(\mathbf{f l})$ & $60,2-69,2$ & $\begin{array}{c}53,9^{\mathrm{ab}} \\
(53,7-54,5)\end{array}$ & $\begin{array}{c}53,7^{\mathrm{ab}} \\
(53,6-54)\end{array}$ & $\begin{array}{c}54,7^{\mathrm{a}} \\
(54,4-55,2)\end{array}$ & $\begin{array}{c}53,1^{\mathrm{b}} \\
(52,9-53,6)\end{array}$ & $0,0117 *$ \\
\hline $\begin{array}{l}\text { Proteína plasmática } \\
\text { total (g/dl) }\end{array}$ & $6,1-7,1$ & $\begin{array}{c}8,2 \\
(7,8-8,4)\end{array}$ & $\begin{array}{c}8 \\
(8-8)\end{array}$ & $\begin{array}{c}7,7 \\
(7,6-7,8)\end{array}$ & $\begin{array}{c}8 \\
(7,8-8)\end{array}$ & 0,297 \\
\hline $\begin{array}{l}\text { Fibrinogênio } \\
\text { (mg/dl) }\end{array}$ & $100-300$ & $\begin{array}{c}200 \\
(200-200)\end{array}$ & $\begin{array}{c}400 \\
(200-400)\end{array}$ & $\begin{array}{c}200 \\
(200-200)\end{array}$ & $\begin{array}{c}200 \\
(200-400)\end{array}$ & 0,0708 \\
\hline 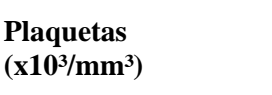 & $837-1455$ & $\begin{array}{c}1189 \\
(1131-1385)\end{array}$ & $\begin{array}{c}1283,5(1185- \\
1312)\end{array}$ & $\begin{array}{c}1313,5(1295- \\
1347)\end{array}$ & $\begin{array}{c}1111,5(939- \\
1237)\end{array}$ & 0,394 \\
\hline $\begin{array}{l}\text { Leucócitos Totais- } \\
\text { valores absolutos } \\
\left(\mathbf{m m}^{3}\right)\end{array}$ & $3,1-9,7$ & $\begin{array}{c}3,5 \\
(3,1-4,9)\end{array}$ & $\begin{array}{c}3,9 \\
(3,9-4,3)\end{array}$ & $\begin{array}{c}5,4 \\
(4,9-5,5)\end{array}$ & $\begin{array}{c}4,9 \\
(4,7-5,4)\end{array}$ & 0,2063 \\
\hline Neutrófilos $\left(\mathbf{m m}^{\mathbf{3}}\right)$ & $93-3104$ & $\begin{array}{c}1495,5(1053- \\
1764)\end{array}$ & $\begin{array}{c}1537,5(1419- \\
2088)\end{array}$ & $\begin{array}{c}2286,5(2058- \\
2365)\end{array}$ & $\begin{array}{c}1550 \\
(1485-1728)\end{array}$ & 0,6216 \\
\hline Eosinófilos - valores & $0-194$ & 75 & 83,5 & 93 & 122,5 & 0,6216 \\
\hline
\end{tabular}




\begin{tabular}{|c|c|c|c|c|c|c|}
\hline absolutos $\left(\mathbf{m m}^{3}\right)$ & & $(64-102)$ & $(80-102)$ & $(93-196)$ & $(84-162)$ & \\
\hline $\begin{array}{l}\text { Linfócitos - valores } \\
\text { absolutos }\left(\mathbf{m m}^{3}\right)\end{array}$ & 1953-9021 & $\begin{array}{c}2032 \\
(1911-2550)\end{array}$ & $\begin{array}{c}1792,5(1482- \\
2448)\end{array}$ & $\begin{array}{l}2832,5(2352- \\
3339)\end{array}$ & $\begin{array}{c}3012,5(2914- \\
3078)\end{array}$ & 0,121 \\
\hline Monócitos (mm³) & $0-776$ & $\begin{array}{c}165,5 \\
(98-184)\end{array}$ & $\begin{array}{c}197,5 \\
(195-258)\end{array}$ & $\begin{array}{c}198,5 \\
(175-294)\end{array}$ & $\begin{array}{c}250,5 \\
(235-294)\end{array}$ & 0,1418 \\
\hline Mastócitos/área & - & $\begin{array}{c}0,000050271^{\mathrm{ab}} \\
(0,000026540- \\
0,000060309)\end{array}$ & $\begin{array}{c}0,000041577^{\mathrm{a}} \\
(0,000031267- \\
0,000043931)\end{array}$ & $\begin{array}{c}0,000047709^{\mathrm{a}} \\
(0,000046686- \\
0,000068626)\end{array}$ & $\begin{array}{c}0,000062081^{\mathrm{bc}} \\
(0,000062426- \\
0,000061736)\end{array}$ & $0,010 *$ \\
\hline $\begin{array}{l}\text { Infiltrado } \\
\text { inflamatório/área }\end{array}$ & - & $\begin{array}{l}0,000519578 \\
(0,000460610- \\
0,000584180)\end{array}$ & $\begin{array}{c}0,000544370 \\
(0,00057865- \\
0,00059895)\end{array}$ & $\begin{array}{c}0,000646978 \\
(0,000375495- \\
0,000718188)\end{array}$ & $\begin{array}{c}0,000569992 \\
(0,000557731- \\
0,000584180)\end{array}$ & 0,4523 \\
\hline
\end{tabular}

Legenda: HCM, hemoglobina corpuscular média. CHCM, concentração de hemoglobina corpuscular média.

Letras diferentes representam diferenças estatisticamente significativas entre os grupos.

Resultados apresentados em mediana (Intervalo Interquartil)

Valor de p obtido pelo Teste de Kruskal Wallis e pós-teste de Dunn para comparação de todos os grupos. Nível de significância de p<0,05.

Source: Autores.

\section{Discussão}

O aumento do CHCM pode ser causado por diversos fatores como: amostras hemolisadas ou lipêmicas, aglutinação de eritrócitos, esferocitose hereditária e osmolalidade anormal (sódio baixo) (Rosenfeld, 2012). Outros autores observaram que após a exposição à pesticidas organofosforados houve diminuição dos valores de CHCM e não aumento, como observado no GAC e GC na presente pesquisa (Fareed et al., 2013).

Resultados semelhantes ao presente trabalho foram encontrados em um estudo que avaliou a exposição crônica oral ao 2,4-D em cães. A exposição foi realizada durante 52 semanas, para 4 grupos, sendo eles expostos as seguintes doses de 2,4-D misturadas na dieta diária dos animais: $0,1,5$ e $7.5 \mathrm{mg} / \mathrm{kg} /$ dia. Os pesquisadores observaram que nenhum grupo apresentou alterações significativas em relação aos parâmetros hematológicos estudados (leucócitos totais, eritrócitos, hematócrito, hemoglobina, plaquetas, CHCM, VCM e HCM) (Charles, Dalgard, Cunny, Wilson \& Bus 1996), sugerindo que as alterações encontradas nos valores de CHCM e VCM na presente pesquisa não foi devido a exposição inalatória ao 2,4-D, visto que o estudo anterior apresentou tempo de exposição maior, comparado ao do presente trabalho, e não observou diferença nesses parâmetros.

Entretanto resultados controversos foram encontrados em um estudo com a exposição subcrônica oral (13 semanas) ao 2,4-D nas formas de ácido, amina e éster, misturados também na ração dos ratos, porém com doses maiores ao trabalho anterior: 0, 1, 15, 100 e $300 \mathrm{mg} / \mathrm{kg} / \mathrm{dia}$. Os resultados do estudo demonstraram que a maior dose de 2,4-D (300 mg/kg) causou a redução dos níveis de hemoglobina, plaquetas e leucócitos totais com diferença estatisticamente significativa comparado ao grupo controle nas três formas de 2,4-D (Charles, Cunny, Wilson \& Bus 1996). Provavelmente a diferença entre os resultados dos estudos está relacionada as doses utilizadas, sendo que a dose de $300 \mathrm{mg} / \mathrm{kg}$ é considerada acima do estabelecido, que para a exposição subcrônica é de $15 \mathrm{mg} / \mathrm{kg} /$ dia (EPA, 2005).

Wafa et al. (2017) também observaram que a exposição subaguda oral (4 semanas) em doses média e alta ao 2,4-D causou diminuição dos níveis de hemoglobina no sangue de ratos, comparado ao grupo controle. Esses autores avaliaram 4 grupos, expostos, respectivamente, a $1 \mathrm{ml}$ de água destilada, 15, 75 e $150 \mathrm{mg} / \mathrm{kg}$ de 2,4-D, porém, diferente dos estudos citados anteriormente, o 2,4-D foi diluído na água que os ratos ingeriam diariamente e não na dieta.

A principal diferença encontrada entre os estudos citados e a presente pesquisa está no tipo de exposição, sendo inalatória e oral, com isso os resultados sugerem que a exposição oral ao herbicida, quando administrado diretamente no 
alimento ou na água em doses maiores que as estabelecidas pela EPA (2005) podem ser mais agressivas aos parâmetros hematológicos comparada a exposição inalatória.

Geralmente a mucosa nasal é a primeira a sofrer lesões por substâncias tóxicas inaladas, sendo um alvo potencial para contaminantes presentes no ar (Yorgancilar, Deveci \& Deveci, 2012). Entretanto, essa relação não foi observada na presente pesquisa, visto que a exposição inalatória ao 2,4-D em um período de 6 meses não causou inflamação da mucosa nasal e aumento dos mastócitos comparado ao grupo controle.

Os mesmos resultados foram encontrados em relação ao infiltrado inflamatório/área em um estudo com exposição aguda ao 2,4-D em camundongos nos períodos de 24, 48, 72 e 192 horas. Ainda na mesma pesquisa não foram encontradas diferenças da quantificação dos mastócitos dos grupos expostos ao 2,4-D comparados ao grupo controle, única diferença encontrada para o grupo de alta concentração no intervalo de tempo de 48 horas, comparado ao de 24 horas, porém sem diferença quando comparado ao grupo exposto a 192 horas, demonstrando que o aumento dos mastócitos pode estar relacionado a dose de exposição, e não ao tempo (Mello et al., 2018).

Uma revisão de literatura, realizada por Ye, Beach, Martin e Senthilselvan (2017), que avaliou a associação entre a exposição a pesticidas e a saúde respiratória na população geral demonstrou que as exposições a defensivos agrícolas organofosforados, inseticidas piretróides e pesticidas organoclorados foram associadas à função pulmonar prejudicada, porém a exposição ao herbicida 2,4-D não apresentou nenhuma associação prejudicial à saúde respiratória, sugerindo que em doses ambientalmente relevantes o herbicida não é tóxico ao sistema respiratório inferior, o que poderia justificar os achados da presente pesquisa.

No estudo de Slager et al. (2009), o glifosato e o 2,4-D foram os herbicidas mais correlacionados a rinite, associado apenas ao uso atual de ambos, e não ao uso pregresso. Porém, esses autores avaliaram a presença de rinite apenas pelos sintomas relatados pelos trabalhadores e não por testes específicos. A rinite pode ser resultado de um resfriado ou de uma doença como a asma, o que não foi considerado no estudo. Pensando nisso, outra pesquisa realizada pelos mesmos autores, ao excluir os trabalhadores com sintomas de rinite que apresentaram episódios de resfriado e/ou asma anteriormente, demonstrou que o 2,4-D não apresentou associação significativa com a presença de rinite (Slager et al., 2010).

Embora não encontramos diferença em relação a quantificação de mastócitos entre o grupo controle e os grupos expostos ao 2,4-D no presente trabalho, não podemos descartar a hipótese da associação da exposição inalatória ao 2,4-D com a presença de rinite, visto que não avaliamos os níveis de imunoglobulina $\mathrm{E}$ (IgE), que é o desencadeante da resposta inflamatória na rinite, sendo considerado uma limitação do nosso estudo.

Assim como não encontramos efeitos tóxicos no presente trabalho, em humanos também não foram observados efeitos adversos crônicos nas pesquisas epidemiológicas resultante em uma revisão de literatura a respeito de doenças como cânceres, alterações reprodutivas, genéticas, neurológicas, hormonais e do sistema imunológico. Além disso, a mesma revisão evidenciou que a maioria da população que apresenta contato direto com o herbicida são os trabalhadores e populações rurais (Burns \& Swaen, 2012).

Como não foi observado diferenças significantes nas variáveis analisadas entre as diferentes concentrações do herbicida, acredita-se que os efeitos do 2,4-D, se surgirem, não sejam dose-dependente. O mesmo fato foi observado por Mello et al (2020), que por meio da exposição inalatória e oral de ratos ao 2,4-D evidenciaram efeitos genotóxicos nos ratos expostos, com danos no DNA, independente das doses do 2,4-D utilizadas em ambos os tipos de exposições.

Não foram encontrados na literatura dados sobre a influência da exposição inalatória crônica ao herbicida 2,4-D nos parâmetros hematológicos e sistema respiratório, somado a isso os resultados encontrados demonstram a necessidade de se ampliar as pesquisas sobre a exposição crônica, principalmente, para poder esclarecer os efeitos nocivos dos defensivos agrícolas. 


\section{Conclusão}

A partir dos resultados obtidos podemos concluir que o herbicida 2,4-D não demonstrou toxicidade aos parâmetros hematológicos e epitélio nasal de ratos Wistar após exposição crônica inalatória, no período de 6 meses, quando comparados ao grupo controle, em concentrações equivalentes às aplicadas no uso agrícola, o que corrobora com a classificação toxicológica do 2,4-D, para exposição inalatória, realizada pela EPA (2005). Além disso, foi possível observar que os efeitos do herbicida não estão associados a concentração exposta. O que não descarta a possibilidade de causar alterações hematológicas e respiratórias se expostos em um período de tempo maior que 6 meses.

Desta forma, sugerimos novas pesquisas sobre o efeito tóxico do herbicida em um tempo maior de exposição com a investigação detalhada de marcadores inflamatórios relacionados com alterações do sistema respiratório e hematológico a fim de esclarecer o comportamento do organismo e sistema imunológico após a exposição ao 2,4-D.

\section{Agradecimentos}

O presente trabalho foi realizado com apoio da Coordenação de Aperfeiçoamento de Pessoal de Nível Superior Brasil (CAPES) - Código de Financiamento 001. Agradecemos à Universidade do Oeste Paulista (UNOESTE) pelo auxílio para a realização desta pesquisa. Aos técnicos do Biotério e do laboratório de análises clínicas do hospital veterinário da Universidade do Oeste Paulista (UNOESTE) pelo serviço prestado e por todo o suporte durante a realização do trabalho.

\section{Referências}

Burns, C. J. \& Swaen, G. M. H. (2012). Review of 2,4-dichlorophenoxyacetic acid (2,4-D) biomonitoring and epidemiology. Critical Reviews in Toxicology,42(9):768-786.

Chaim, A. (2004). Tecnologia de aplicação de agrotóxicos: fatores que afetam a eficiência e o impacto ambiental. In: Silva, C. M. M. S \& Fay, E. F. (Org). Agrotóxicos \& ambiente (Cap. 8, pp. 289-317) Brasília: Embrapa.

Charles, J. M., Cunny, H. C., Wilson, R. D. \& Bus, J. S. (1996). Comparative Subchronic Studies on 2,4-Dichlorophenoxyacetic Acid, Amine, and Ester in Rats. Toxicological Sciences, 33(2):161-165.

Charles, J. M., Dalgard, D. W., Cunny, H. C., Wilson R. D.., \& Bus, J. S. (1996). Comparative subchronic and chronic dietary toxicity studies on 2,4dichlorophenoxyacetic acid, amine, and ester in the dog. Fundamental and Applied Toxicology, 29(1):78-85.

Dakhakhni, T. H., Raouf, G. A. \& Qusti, S. Y. (2016). Evaluation of the toxic effect of the herbicide 2, 4-D on rat hepatocytes: an FT-IR spectroscopic study. European Biophysics Journal, 45(4): 311-20.

Fareed, M., Pathak, M. K., Bihari, V., Kamal, R., Srivastava, A. K. \& Kevasachandran, C. N. (2013). Adverse respiratory health and hematological alterations among agricultural workersoccupationally exposed to organophosphate pesticides: a cross-sectional study in North India. PLoS One, 8(7):e69755.

Ferreira, M. L. P. C. (2015). A pulverização aérea de agrotóxicos no Brasil: Cenário atual e desafios. Revista de Direita Sanitário, 15(3): 18-45.

Koche, J. C. (2011). Fundamentos de metodologia científica: teoria da ciência e iniciação à pesquisa. Vozes.

Londres, F. (2011). Agrotóxicos no Brasil: Um guia para ação em defesa da vida. AS-PTA - Assessoria e Serviços a Projetos em Agricultura Alternativa.

Mello, F. A., Silva, B. B. M., Barreiro, E. B. V., Franco, I. B., Nogueira, I. M., Chagas, P. H. N., Parizi, J. L. S., Pereira, D. R., Rossi, R. C., Nai, G. A. (2020). Evaluation of genotoxicity after acute and chronic exposure to 2,4-dichlorophenoxyacetic acid herbicide (2,4-D) in rodents using machine learning algorithms. The Journal of Toxicological Sciences, 45(12):737-750.

Mello, F. A., Quinallia, G., Marion, A. C., Jorge, F. C., Marinelli, L. M., Salge, A. K. M., Fagiani, M. A. B., Mareco, E. A., Favareto, A. P. A. \& Rossi e Silva, R. C. (2018). Avaliação da cavidade nasal de camundongos submetidos à exposição ao herbicida ácido 2,4-diclorofenoxiacético. Medicina (Ribeirão Preto), 51(4):247-53.

Pedroso, D. O., Silva, B. F., Agostinetto, L., Evaristo, A., Siegloch, A. E. (2020). Manejo de agrotóxicos no cultivo de grãos e sua relação com a saúde e ambiente. Research, Society and Development, 9(10):e8399108282.

Pignati, W. A., Lima, F. A. N. S., Lara, S. S., Correa, M. L. M., Barbosa, J. R., Leão, L. H. C., Pignati, M. G. (2017). Distribuição espacial do uso de agrotóxicos no Brasil: uma ferramenta para a Vigilância em Saúde. Ciência \& Saúde Coletiva, 22(10):3281-93.

Rosenfeld, R. (2012). Hemograma. Jornal Brasileiro de Patologia e Medicina Laboratorial, 48(2):244.

Slager, R. E., Poole, J. A., Levan, T. D., Sandler, D. P., Alavanja, M. C. \& Hoppin, J. A. (2009). Rhinitis associated with pesticide exposure among commercial pesticide applicators in the agricultural health study. Occupational and Environmental Medicine, 66(11):718-24. 
Research, Society and Development, v. 10, n. 11, e282101119607, 2021

(CC BY 4.0) | ISSN 2525-3409 | DOI: http://dx.doi.org/10.33448/rsd-v10i11.19607

Slager, R. E., Simpson, S. L., Levan, T. D., Poole, J. A., Sandler, D. P. \& Hoppin, J. A. (2010). Rhinitis associated with pesticide use among private pesticide applicators in the agricultural health study. Journal of Toxicology and Environmental Health, Part A, 73(20):1382-93.

Ueda, R. M. R., Souza, V. M., Magalhães, R. L., Giuffrida, R., Nai, G. A. (2021). Alteração da memória de reconhecimento de objetos após exposição crônica ao ácido diclorofenoxiacético (2,4-D) em ratos adultos. Research, Society and Development, 10(1):e23310111695.

U.S. United States Environmental Protection Agency (EPA). (2005). 2,4 RED facts. https://www3.epa.gov/pesticides/chem_search/reg_actions /reregistration/fs_PC-030001_30-Jun-05.pdf

Wafa, T., Amel, N., Issam, C., Imed, C., Abdelhedi, M. \& Mohamed, H. (2017). Subacute effects of 2,4-dichlorophenoxyacetic herbicide on antioxidant defense system and lipid peroxidation in rat erythrocytes. Pesticide Biochemistry and Physiology, 99(3):256-64.

Ye, M., Beach, J., Martin, J. W. \& Senthilselvan, A. (2017). Pesticide exposures and respiratory health in general populations. Journal Environmental of Science (China), 51:361-70.

Yorgancilar, E., Deveci, E. \& Deveci, S. (2012). Effects of Formaldehyde on Respiratory Mucosa in Rats. International Journal of Morphology, 30(2):521-23. 